\title{
NATURAL GAS CONVERSION PROCESS
}

PROJECT:Build a Laboratory Apparatus and Operate it to provide Data for a Large-scale Gas Conversion Frocess

Contract: DE-FG01-90CE 15459

\section{FOURTH QUARTERLY REPORT}

\section{ABSTRACT:}

Work continued on Task No.3. Particular attention was given to the back pressure control at the two gaseous effluent outlets and to the incineration of these effluents prior to their disposal.

Temperature of the riser/regenerator and steam requirements were predicted from the gasification kinetics of coke and of coal char experimentally determined at atmospheric pressure,but at somewhat lower temperatures by H.Heinemann et al in Ref.14 and by T.Adschiri et al.in $\operatorname{Ref.15.}$

The results of interactions of $\mathrm{CH} 4$ molecules with a Hydrogen Plasma in the adsorbed layer at the surface of refractory oxides in Ref. 6 were compared with those in the gas phase in Ref.16 in order to select the optimum temperature range in the Cyclone reactor.

\section{4-BACK PRESSURE CONTROL ON EFFLUENT STREAMS}

The gaseous effluent from the Cyclone reactor is quenched in a 
water-cooled heat ex:hanger and the liquid product is condensed in a . Liquid Nitrogen-cocied trap. The unreacted $\mathrm{CH}_{4}$, together with $\mathrm{H} 2$ and $\mathrm{C2}$ gaseous products is discharged at the base of a tube immersed in a water column and collected above the water, at atmospheric pressure.

Similarly, the gaseous effluent from the riser cyclone,containing steam, $\mathrm{CO}, \mathrm{CO} 2$ and $\mathrm{H} 2$ is discharged at the base of a tube immersed in a water column and the permanent gases $\mathrm{CO}, \mathrm{CO} 2, \mathrm{H} 2$ are collected above the water, at atmospheric pressure.

Both residual streams at atmospheric pressure are then mixed and sent to the burner of an incinerator with a large excess of combustion air.

The incinerator is a conventional gas water heater, delivering a relatively low temperature flue gas to the upper part of a ventilated hood,for release to the atmosphere, while the hot water produced is discharged to the sink. (see Fig.17)

\section{5-STEAM GENERATOR}

The steam required for the riser/regenerator is produced in an autoclave regulated at a constant pressure above atmospheric. The mass flow rate of steam into the riser/regenerator is obtained by feeding a weighted stream of water into the autoclave.The saturated steam from the autoclave becomes superheated in the riser/regenerator which is maintained at a much higher temperature than the autoclave by an electric furnace. This high temperature is required to obtain a sufficiently high rate of gasification of the coke on the spent catalyst.

3.6-DESIRABLE RANGE OF OPERATING CONDITIONS FOR THE RISER/REGENERATOR 
Heinneman et al,in Ref. 14 have shown that the gasification of coke and coal chars into $\mathrm{CO} 2$ and $\mathrm{H} 2$ is possible at very moderate temperatures $(230 \mathrm{C}-525 \mathrm{C}$ ) in the presence of highly basic oxide catalysts but the conversion rate is quite low, leading to only $10 \%$ conversion of graphite after 2 hours, with a rate of $0.6 \mathrm{~mol} / \mathrm{mol} / \mathrm{min}$. The rate determining step is the $C-C$ bond breaking next to a surface Carbon/Oxygen complex.By operating the riser/regenerator at about $1,000 \mathrm{C}$, it is possible, however to increase the conversion rate about one hundredfold, thus reducing the catalyst's residence time to a more acceptable level of one minute or less.Experiments on the gasification of coal chars and of refinery cokes show much higher rates than those on graphite. In Ref.15,T.Adshiri et al. show that the rate is directly related to the number of active sites on these samples. This number increases with th? surface area of the sample,temperature and partial pressure of the oxidizing reactant (steam or $\mathrm{CO2}$ ). In view of the high surface area of the catalyst support,coke deposits also exhibit a high surface area and the operating conditions in the riser/regenerator (high temperature and high partial pressure of steam) are all favorable to higher gasification rates, which may further reduce to about $10 \mathrm{~s}$ the required residence time of catalyst particles in the riser/regenerator.

3.7-DESIRABLE RANGE OF OPERATING CONDITIONS FOR THE CYCLONE REACTOR In his thesis,M.Nikravetch (Ref.6) provides the analysis of the products resulting from cracking of $\mathrm{C} 16$ in the presence of a Hydrogen plasma for various temperatures of the spouting bed of Alumina particles and for residence times of the hydrocarbon feed ranging from $0.15 \mathrm{~s}$ to $0.27 \mathrm{~s}$. These results have been re-interpreted in term of the 
C5+ yield. The conditions leading to a maximum yield of C5+ distillate. fractions are for the maximum bed temperature (971 K) and minimum residence time $(0.155 \mathrm{~s})$ when all other operatring parameters are maintained essentially constant. Under these conditions, the selectivity to C5+ reaches nearly $50 \%$, for a cracking efficiency of about $50 \%$. In order to minimize the selectivity to heavier hydrocarbons in the conversion of $\mathrm{CH} 4$ to liquid hydrocarbons, while favoring the conversion into distillates, it appears that our next experiments should extend to a bed temperature range (about $700 \mathrm{C}$ ) which is somewhat lower than that used in previous tests $(800 \mathrm{C}-1150 \mathrm{C})$ and that the residence time could be increased to about $0.15 \mathrm{~s}$. Under those conditions, the desirable distillate fractions (C5 to C12) may reach a yield of more than $20 \%$, on a weight basis. This would approach the economic threshold for the process.

\section{8-COMPARISON WITH GAS PHASE PLASMA PYROLYSIS}

In Ref.16, Baronnet et al have also produced the cracking of $\mathrm{C} 16$ in the presence of a hyarogen plasma.Their reaction, however, takes place in the gas phase,by direct interaction of a vaporized C16 stream with the plasma jet. In that case, the product slate is very different from that obtained by M.Nikravech with reactions occurring in the adsorbed phase at the surface of Alumina particles. The gas phase reaction products are then essentially $\mathrm{C} 2$ and $\mathrm{C} 4$ hydrocarbons, with a very low selectivity $(<2 \%$ w) to the desirable C5-C12 fractions.This shows the importance of ising a fuidized bed of particles of a metal oxide as a quenching medium to drive the reactions of the intermediate radicals towards the formation of distillate molecules, rather than towards the formation of acetylene and light hydrocarbons. 


\section{REFERENCES}

14) Fundamental Studies of Catalytic Gasification,by H.Heinemann and G.A.Somorjai,Topical Report LBL-30015 UC 109, June 1991

15) Characterization of Coal Char Gasification Rate,by T.Adschiri, T.Nozaki,T.Furusawa and Zhu Zi-bin, AIChE Journal,VoI.37, No.6, P.897 June 1991

16) $\mathrm{H} 2 / \mathrm{CH} 4$ arc plasma:application to the hydropyrolysis of heavy oils by Baronnet, J.M., Lesinki, J.A., B.Sauvage, A.Sanon, E.Meillot, Rev.Int. Hautes Temperatures et Refractaires,Vol.6,P.9,1990

\section{DISCLAIMER}

This report was prepared as an account of work sponsored by an agency of the United States Government. Neither the United States Government nor any agency thereof, nor any of their employees, makes any warranty, express or implied, or assumes any legal liability or responsibility for the accuracy, compieteness, or usefulness of any information, apparatus, product, or process disclosed, or represents that its use would not infringe privately owned rights. Reference herein to any specific commercial product, process, or service by trade name, trademark, manufacturer, or otherwise does not necessarily constitute or imply its endorsement, recommendation, or favoring by the United States Government or any agency thereof. The views and opinions of authors expressed herein do not necessarily state or reflect those of the United States Governmeni or any agency thereof. 


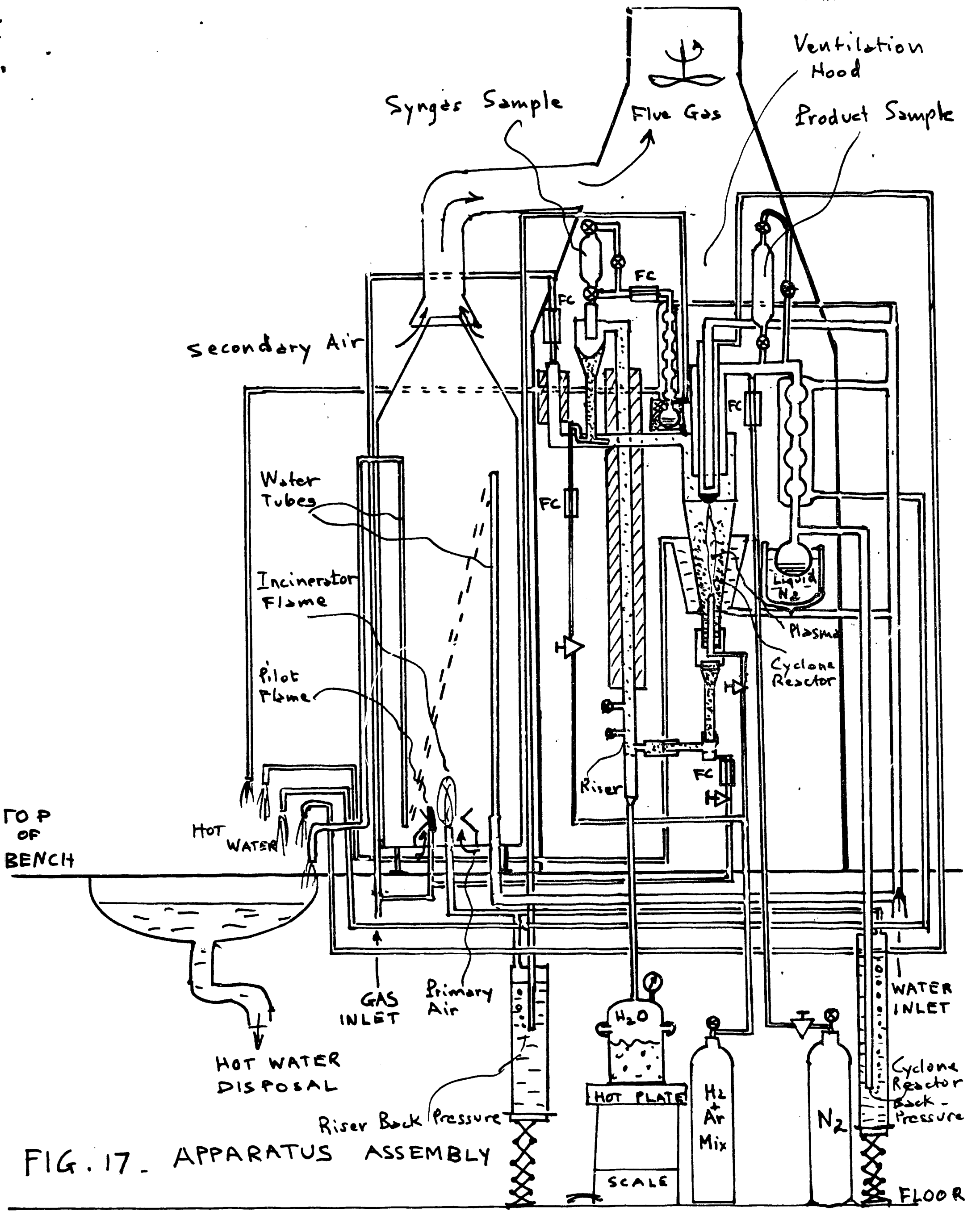



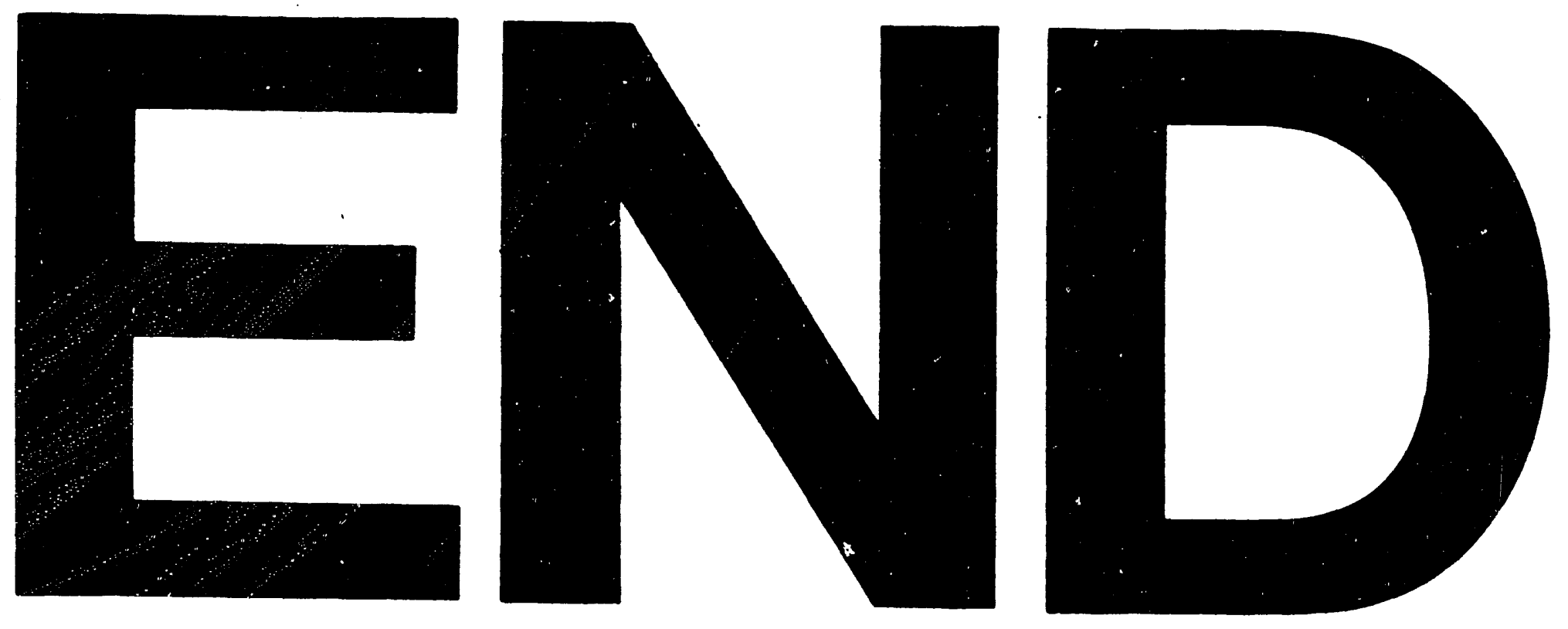

1
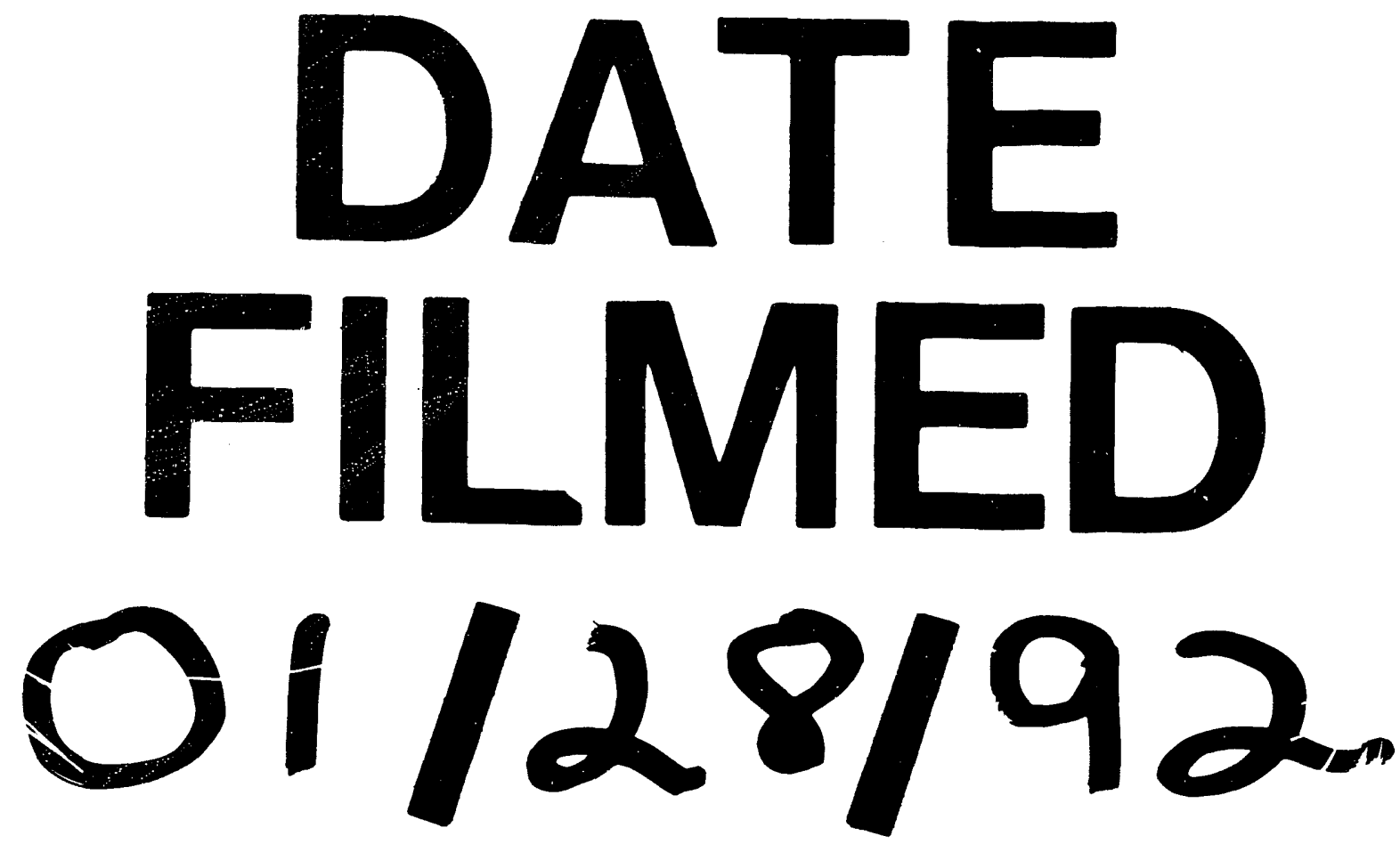
